\title{
Analysis of the Physical Education and Sports Studying Students Physical Development State in the Far North of Russia
}

\author{
Abramova V.R. \\ Department of natural disciplines \\ Churapcha State Institute of Physical Education and Sports \\ Churapcha, Russia \\ vladrom09@mail.ru
}

\author{
Kuzmina S.S. \\ Institute of natural sciences \\ M.K. Ammosov North-Eastern Federal University \\ Yakutsk, Russia \\ sskuzmina@bk.ru
}

\author{
Korkin E.V. \\ Department of natural disciplines \\ Churapcha State Institute of Physical Education and Sports \\ Churapcha, Russia \\ korkin.e@mail.ru
}

\begin{abstract}
This study describes the state of Yakut national Institute physical culture and sports students physical development, operating in the Far North of Russia. One hundred and eighteen students ( 58 boys and 60 girls) aged 18-20 years, who are studying in the 1st, 2nd, 3rd year, participated in the study. Data on body length, weight, chest circumference, vital index, body strength index were analyzed on the basis of regional body centile intervals performance standards. The students ' physical development is characterized by differences in somatotypes performance and low physiometric indicators.
\end{abstract}

Keywords—physical development; life index; body strength

\section{INTRODUCTION}

The level of a person physical development depends on many factors, which include geographical, socio-economic, psychological, traditions of education, etc., and reflects the adaptation to the environment. Adaptation of the indigenous population of the Far North to the extreme climatic conditions of the living environment formed a certain set of General morpho-physiological characteristics that developed in the course of centuries of evolution [16]. Taking into account anthropometric features of indigenous populations of $\mathrm{T}$. I. Alekseeva Arctic highlights the Arctic adaptive type [17]. For the indigenous inhabitants of the Far North, the researchers note mesomorph features of the body: a relatively large body weight with a small length $[2,4,16,17]$, a significant development of the chest [17].
Students, united by an organized educational process and way of life, make up a special social group. Therefore, it can be argued that their physical development is a feature that reflects the regional characteristics of the youth population physical health. In addition, quantitative assessment of physical condition provides valuable information about physical health and functional capabilities of the body. It allows to adjust the volume of organized physical activity and planning of certain physical activities in the educational process $[1,8,10,11]$.

Churapcha State Institute of Physical Education and Sports is a unique educational institution, it is the first of its kind and only higher education institution that operates in rural areas in extreme climatic conditions of the Far North. The Institute is located in the village Churapcha of the Republic of Sakha (Yakutia), located in the Central part of Yakutia. The climate of Central Yakutia is sharply continental, with long harsh winters and short warm summers. The coldest month of the year is January with an average monthly temperature of $41.4^{\circ} \mathrm{C}$., and persistent frosts last 207 days in the middle. According to the scheme of medico-geographical zoning adopted in Russia, this area belongs to an uncomfortable zone in which only $40-50 \%$ of days a year have favorable weather for human life [12].

Currently, there is evidence that the level of physical health and physical fitness of students is very low $[3,7,9,13$, 15]. According to experts, the state of modern students health is characterized by the following features: an increase in 
somatic diseases, deviations in mental health, a decrease in physical development $[13,14,18]$. The activity of students in the process of learning and training at the University of physical culture and sports is associated with increased physical activity. The impact of severe climatic conditions on the body of students of the Northern Institute is of great importance. These factors lead to nervous and emotional stress, to a complex restructuring of homeostatic systems of the body $[19,20]$.

Taking into account the above-mentioned reasons, the Department of natural Sciences of the Institute annually monitors the physical development and functional state of the students' body in all areas of training.

The purpose of the study - is to identify the features of physical development of physical culture and sports students of higher educational institutions, studying in rural areas of the Far North.

\section{RESEARCH METHODOLOGY}

In our research anthropometric, physiological and standard and index methods were used. The length of the subjects' bodies was recorded using the electronic height meter Seca (Russia), and the body weight (BW) was measured using floor scales. The circumference of the chest (COC) was measured using a centimeter tape. The vital lung capacity (VLC) was determined using the Micro laboratory spirometer. According to the obtained results the calculated indices: life index ( $\mathrm{LI}=\mathrm{VLC} / \mathrm{BW}$ ), index of Pin'e (conventional unit, c.u.) to determine the strength of the body (the Index of Pin'e = height-(BM+COC(exhale)). The obtained values of LM compared with the norm for men is $60-70 \mathrm{ml} / \mathrm{kg}$, women - 50$55 \mathrm{ml} / \mathrm{kg}$. Obtained values of indicators of the Tower was evaluated by the scale: $<10$ - a good body; 10-20 is a good figure; 21-25 - average; 26-35 - weak physique [5].

The research was carried out on the basis of Churapcha State Institute of Physical Education and Sports of the Republic of Sakha (Yakutia). The study involved 118 students ( 58 boys and 60 girls) of Yakut nationality from the first to the third year students. The age of students ranged from 18-20 years.

Statistical analysis of group values was carried out according to student's t-criterion.

\section{RESULTS}

The results are presented in table 1, to characterize the overall physical development of the students used a centile analysis for the distribution of the number of the received data compared to the standard for representatives of Yakut nationality. Regional standards of human health in the North were developed in 2001 as a result of the Republic of Sakha (Yakutia) of the population studies by the Institute of health of the Yakut scientific center [6] (tables 3, 4).
TABLE I. INDICATORS OF GIRLS PHYSICAL DEVELOPMENT

\begin{tabular}{|c|c|c|c|}
\hline \multirow{2}{*}{ Index } & \multicolumn{3}{|c|}{ Girls } \\
\cline { 2 - 4 } & 1 course & 2 course & 3 course \\
\hline Body length, cm & $157,5 \pm 1,0$ & $159,5 \pm 0,6$ & $159,8 \pm 1,4$ \\
\hline Body weight, kg & $57,9 \pm 1,4$ & $53,4 \pm 1,6$ & $55,4 \pm 1,1$ \\
\hline VLC, 1 & $2,2 \pm 0,07$ & $2,14 \pm 0,07$ & $2,3 \pm 0,07^{*}$ \\
\hline COC (Rest), cm & $88,1 \pm 1,3$ & $84,1 \pm 1,3^{*}$ & $83,2 \pm 1,0$ \\
\hline COC (Inhale), cm & $88 \pm 1,1$ & $86,6 \pm 2,4^{*}$ & $87,7 \pm 1,5$ \\
\hline COC (Exhale), cm & $92,9 \pm 1,4$ & $79,5 \pm 2,2^{*}$ & $81,6 \pm 1,3$ \\
\hline Life index, m1/kg & $38,6 \pm 1,65$ & $43 \pm 4$ & $43,3 \pm 1,5^{*}$ \\
\hline Index Pin'e, c.u. & $12,3 \pm 2,5$ & $25,6 \pm 3,2^{*}$ & $22,4 \pm 2,2^{*}$ \\
\hline
\end{tabular}

* Significant differences with the previous group $(\mathrm{p}<0,05)$ (Table footnote)

TABLE II. INDICATORS OF YOUTHS PHYSICAL DEVELOPMENT

\begin{tabular}{|l|c|c|c|}
\hline \multirow{2}{*}{ Index } & \multicolumn{3}{|c|}{ Youths(boys) } \\
\cline { 2 - 4 } & $\mathbf{1}$ cours $\boldsymbol{c}$ & $\mathbf{2}$ cours $\boldsymbol{e}$ & $\mathbf{3}$ cours $\boldsymbol{~}$ \\
\hline Body length, cm & $172,3 \pm 5,5$ & $169,1 \pm 4,0^{*}$ & $175,2 \pm 5,8^{*}$ \\
\hline Body weight, kg & $65,9 \pm 6,5$ & $64,9 \pm 7,5$ & $69,5 \pm 6,6^{*}$ \\
\hline VLC, 1 & $3,3 \pm 0,8^{*}$ & $3,6 \pm 0,7$ & $3,7 \pm 0,4^{*}$ \\
\hline COC (Rest), cm & $90,7 \pm 5,7$ & $89,6 \pm 5,8$ & $91,9 \pm 5,3$ \\
\hline COC (Inhale), cm & $95,5 \pm 5,8$ & $95,0 \pm 6,4$ & $96,6 \pm 4,9^{*}$ \\
\hline COC (Exhale), cm & $87,3 \pm 5,6$ & $86,9 \pm 7,2$ & $89,2 \pm 4,8^{*}$ \\
\hline Life index, ml/kg & $50,5 \pm 11,4$ & $53,3 \pm 15,3$ & $53,0 \pm 6,1$ \\
\hline Index Pin'e, c.u. & $19,1 \pm 0,9$ & $17,3 \pm 1,5^{*}$ & $14,7 \pm 0,9^{*}$ \\
\hline
\end{tabular}

* Significant differences with the previous group $(\mathrm{p}<0,05)$ (Table footnote)

TABLE III. INDIVIDUAL INDICATORS OF GIRLS PHYSICAL DEVELOPMENT, \%

\begin{tabular}{|c|c|c|c|c|c|}
\hline \multirow{3}{*}{\begin{tabular}{|l|}
\multicolumn{1}{|c}{ Index } \\
$\begin{array}{l}\text { Body } \\
\text { length, cm }\end{array}$
\end{tabular}} & \multicolumn{2}{|l|}{ Centile interval } & \multirow{2}{*}{$\begin{array}{c}1 \text { course } \\
0\end{array}$} & \multirow{2}{*}{$\begin{array}{c}2 \text { course } \\
0\end{array}$} & \multirow{2}{*}{\begin{tabular}{|c|}
3 course \\
8,3
\end{tabular}} \\
\hline & Lowest & $147,7-151,1$ & & & \\
\hline & Below average & $151,2-155,4$ & 14,2 & 0 & 25 \\
\hline & Medium & $155,5-164,4$ & 71,4 & 90 & 58,3 \\
\hline & Above average & $164,5-167,5$ & 0 & 0 & 0 \\
\hline & Highest & $197,6-172,3$ & 14,2 & 10 & 8,3 \\
\hline \multirow{5}{*}{$\begin{array}{l}\text { Body } \\
\text { mass, kg }\end{array}$} & Lowest & $37,0-45,0$ & 0 & 10 & 8,3 \\
\hline & Below average & $45,1-48,1$ & 0 & 20 & 8,3 \\
\hline & Medium & $48,2-57,9$ & 78,6 & 50 & 50 \\
\hline & Above average & $58,0-64,6$ & 21,4 & 20 & 25 \\
\hline & Highest & $64,7-72,1$ & 0 & 0 & 8,3 \\
\hline \multirow[t]{5}{*}{$\mathrm{COC}, \mathrm{cm}$} & Lowest & $67,1-76,0$ & 0 & 40 & 16,7 \\
\hline & Below average & $76,1-78,3$ & 0 & 10 & 8,3 \\
\hline & Medium & $78,4-87,4$ & 85,7 & 40 & 58,3 \\
\hline & Above average & $87,5-91,2$ & 14,3 & 0 & 16,7 \\
\hline & Highest & $91,3-95,9$ & 0 & 10 & 0 \\
\hline
\end{tabular}


TABLE IV. INDIVIDUAL INDICATORS OF PHYSICAL DEVELOPMENT OF YOUTHS, \%

\begin{tabular}{|c|c|c|c|c|c|}
\hline Index & \multicolumn{2}{|c|}{ Centile Interval } & 1 course & 2 & 3 \\
\hline \multirow{5}{*}{$\begin{array}{c}\text { Body } \\
\text { length, } \mathrm{cm}\end{array}$} & Lowest & $158-162$ & 9,5 & 5,3 & 11,8 \\
\hline & Below average & $163-166$ & 4,8 & 26,2 & 41,2 \\
\hline & Medium & $167-175$ & 52,4 & 63,2 & 29,4 \\
\hline & Above average & $176-180$ & 33,3 & 5,3 & 17,6 \\
\hline & Highest & $181-186$ & 0 & 0 & 0 \\
\hline \multirow{5}{*}{$\begin{array}{c}\text { Body } \\
\text { weight, kg }\end{array}$} & Lowest & $40-50,3$ & 0 & 0 & 0 \\
\hline & Below average & $50,4-54,5$ & 42,8 & 10,5 & 35,3 \\
\hline & Medium & $54,6-66,2$ & 52,4 & 63,2 & 41,2 \\
\hline & Above-average & $66,3-74,2$ & 4,8 & 15,8 & 23,5 \\
\hline & Highest & $74,283,4$ & 0 & 10,5 & 0 \\
\hline \multirow[t]{5}{*}{$\mathrm{COC}, \mathrm{cm}$} & Lowest & $73,0-79,8$ & 57,1 & 89,4 & 47,1 \\
\hline & Below average & $79,9-82,5$ & 28,6 & 15,8 & 52,9 \\
\hline & Medium & $82,6-91,2$ & 14,3 & 15,8 & 0 \\
\hline & Above-average & $91,3-96,4$ & 0 & 0 & 0 \\
\hline & Highest & $96,5-102,2$ & 0 & 0 & 0 \\
\hline
\end{tabular}

The evaluation of the average values of physical development indicates the ambiguity of the results:

1. The average length of the body in all groups of girls and boys corresponds to the average level. At the same time, the average growth of boys of the 3rd year is higher by $2.9 \mathrm{~cm}$ compared to the 1 st course and by $6.1 \mathrm{~cm}$ - compared to the 2nd course. In terms of average body weight, the average level is observed in girls of 1,2 and 3 courses, in boys of 1 and 2 courses, above average - in boys of 3 courses in accordance with the regional standard. There is no significant difference between the groups. The average $\mathrm{COC}$ alone corresponds to the average level in a group of 2 girls, 3 boys and rate 1,2 rate; in the group of girls of 1 year and boys of 3 these two courses were above average. The difference in girls the 1 year was $4 \mathrm{~cm}$ compared to 2 rate and $4.9 \mathrm{~cm}$ compared with the 3 course.

2. Indicators of average lung capacity and life index in all studied groups of girls and boys are below the Russian standard.

3. Index pine in groups of 2 girls and 3 course indicators corresponds to medium strength body. In the female group of 1 course obtained significantly low index that points to the strong body type. In three groups of young men, the Pine index corresponds to a strong body type.

\section{DISCUSSION}

Among all indicators of physical development, body length is one of the main indicators. According to the results of the study on the indicator of body length in students of both sexes there is an increase in the 3rd year. The average body length in all groups corresponds to the average statistical body length of Yakut nationality men and women [7]. According to individual indicators, boys in groups 1st and 2nd are dominated by the average level of body length, and in group 3 - the level of "below average". In girls in all three groups, more than $50 \%$ have an average body length. It can be noted that among boys and girls of the 1st year there is a tendency to increase growth: $14 \%$ of girls have a high level of growth, $33 \%$ of boys - the level above average.

Body weight is directly dependent on the length of the body and indirectly reflects the development of the musculoskeletal system, subcutaneous fat layer, being one of the indicators of the environmental and social factors impact on the human body. According to body weight, we found a gradual increase in the parameters of students with age. Most boys and girls have an average level of body weight. The level below the average was found in almost half of the 1st year boys and a third of the 3rd year boys. And in girls in all groups, more than $20 \%$ of respondents have a body weight above average. The circumference of the chest in combination with indicators of length and body weight characterize the socalled total body size.

This indicator characterizes the volume of the body, the development of the thoracic and spinal muscles, as well as the functional state of the chest cavity. Among the groups studied, more than half of the first and second groups and almost half of the third group of young men have the value of COC at a low level, and the rest - at the level of "below average". Unlike boys, the majority of girls have an average COC level, and in group 1 and 3 more than $10 \%$ of respondents have a level "above average". Vital capacity of the lungs, characterizing the function of external respiration, is also one of the physical development indicators. Our study revealed low rates of VLC in all groups of boys and girls. According to the research of many scientists, the northerners have low indices of VLC [2,3], which is also confirmed by the results of our study: students in all three groups of VLC is below the standard values for sports [6]. Given that the average value of VLC is significantly lower than normal in all groups, and body weight has an average level, the average value of the life index in all studied groups was lower than normal. This means that, in General, students are at risk of deteriorating health.

At the index Tower (pine) in two groups of girls revealed the average fortress build. In the group of girls of the 1st year and boys of three groups according to our data obtained significantly low index. It indicates a strong body type $(\mathrm{p}<0,05)$.

\section{CONCLUSION}

A comparative analysis of the students physical development revealed deviations from the standard in the distribution of centile estimates of total body size. In girls and boys of the 1st year, the body length has a weakly pronounced right-hand displacement, and in all other groups there is lefthand asymmetry. The distribution of body weight and chest girth in boys have left - sided asymmetry, and in girls on the contrary-right-sided. The circumference of the chest at rest in most students shows low values, probably due to the weak development of the chest and back muscles. The vital capacity of the lungs in all studied students does not correspond to the normal. Thus, the physical development of students 18-20 
[11] L. Kharitonova, "Features of the physical state of the body of students living in the Far North", Omsk: Publishing house of the Siberian state University of physical culture. 2006, 210.

performance and low physiometric indicators.

\section{References}

[1] Adhikari Anup, Pervin Nahida, Rumy Nazrul Islam, Ali Kitab, Importance of Anthropometric Characteristics in Athletic Performance from the Perspective of Bangladeshi National Level Athletes' Performance and Body Type, American Journal of Sports Science and Medicine. 2014, vol. 2, 4, pp.123-127.

[2] A. Ducros, Adiposite et densite corporelle dune population arctique (eskimo ammasalimiut), Anthropologie. 1971, vol.75, pp.239-254.

[3] V. Abramova, A. Danilova and E. Korkin, Monitoring of physical development of students of sports high school in the North, the Theory and practice of physical culture. 2017, vol. 3, pp. 12-13.

[4] V. E. Deryabin, A. L. Purundzhan, "Geographical features of the body structure of the Soviet population", Moscow: MSU publishing House. $1990,192$.

[5] V. Dubrovsky, "Sports medicine: textbook for University students", Moscow: Vlados. 1999, 365.

[6] V. Krivoshapkin, V Alekseev, P Petrov, "Regional standards of human health in the North (in tables and figures)", Yakutsk: Publishing Department of primary and secondary vocational education Ministry of education of the Republic of Sakha (Yakutia)). 127.

[7] E. V. Egorycheva, Characteristics of physical development, functional state and physical fitness of female students with body weight deficit, Theory and practice of physical culture. 2014, vol. 10, pp. 23-26.

[8] I. Marangoz, S. M. Var, The Comparison of Somatotype Structures in Students Studying at Different Departments of Physical Education, Journal of Education and Training Studies. 2018, vol. 6, 9, pp. 108-112.

[9] L.I. Alexandrova and O.N. Moskovchenko, Optimization of physical activity of students and athletes living in Siberia, based on the assessment of physical condition, Theory and practice of physical culture. 2011, vol. 7 pp. 21-25.

[10] Liliana-Elisabeta Radu, Ileana-Monica Popovici, Alexandru-Rareş Puni, Comparison of Anthropometric Characteristics Between Athletes and Non-athletes, Procedia - Social and Behavioral Sciences. 2015, vol. 191, pp. 495- 499.
[12] N. I. Konysheva, "Climate Of Russia", St. Petersburg: Gidrometeoizdat. 2001, 540.

[13] P. Liu, Z. Ye, H. Lu, J. Lu, L. Huang, J. Gong, Q. Deng, L. Xu, Association between body mass index (BMI) and vital capacity of college students of Zhuang nationality in China: a cross-section study, Oncotarget. 2017, vol. 8(46), pp. 80923-80933. DOI: https://doi:10.18632/oncotarget.20758. Netto, Energy balance and body composition in student athletes, Revista Brasileira em Promocao da Saude. 2016, vol. 29, 3, pp. 422-430.

[15] S. S. Kuzmina, V. R. Abramova, N. N. Sivtsev and E. V. Korkin, Special endurance rating in freestyle wrestling, Theory and practice of physical culture. 2018, vol. 8, pp. 31-32.

[16] T. E. Uvarova, T. E. Burtseva, T. S. Neustroeva and M. S. Savvina, Morphological and physiological features of the indigenous population of the Far North, Far East medical journal. 2009, vol. 2, pp. 114-118. Moscow: Thought. 1977, 322.

[18] Kim-Kimen A.N., Kuznetsova Z.M. The development of the traditions of ancestors to the glory of the Yakut sports. The Russian Journal of Physical Education and Sport. 2018, vol. 13(2), pp. 119-123. DOI: 10.14526/02_2018_319.

[19] Alexsandr S. Kuznetsov. Russian Professor's meeting. Russian Journal of Physical Education and Sport. 2019, 14(1), pp. 17-22. DOI: 10.14526/2070-4798-2019-14-1-18-24

[20] Z. A. Soulliard, A. A. Kauffman, H. F. Fitterman-Harris, J. E. Perry, M. J. Ross, Examining positive body image, sport confidence, flow state, and subjective performance among student athletes and non-athletes, Body Image. 2019, vol. 28, pp. 93-100. DOI: https://doi.org/10.1016/j.bodyim.2018.12.009.
[14] R. C. Matos, S. D. Góes, J. M. Reinaldo, M. M. Leite, R. S. Mendes-

[17] T. I. Alekseeva, "Geographical environment and human biology", 